\title{
Iron-induced changes in pyruvate metabolism of Tritrichomonas foetus and involvement of iron in expression of hydrogenosomal proteins
}

Department of Parasitology, Faculty of Science, Charles University, Viničná 7, Prague, 12844 Czech Republic

\author{
Štěpánka Vaňáčová, Dominique Rasoloson, Jakub Rázga, Ivan Hrdý, \\ Jaroslav Kulda and Jan Tachezy
}

Author for correspondence: Jan Tachezy. Tel: +4202 21953207. Fax: +4202 24919704.

e-mail: tachezy@natur.cuni.cz

Keywords: Tritrichomonas foetus, iron, carbohydrate metabolism, hydrogenosome, transcription

The main function of the hydrogenosome, a typical organelle of trichomonads, is to convert malate or pyruvate to $\mathrm{H}_{2}, \mathrm{CO}_{2}$ and acetate by a pathway associated with ATP synthesis. This pathway relies on activity of iron-sulfur proteins such as pyruvate: ferredoxin oxidoreductase (PFOR), hydrogenase and ferredoxin. To examine the effect of iron availability on proper hydrogenosomal function, the metabolic activity of the hydrogenosome and expression of hydrogenosomal enzymes were compared in Tritrichomonas foetus maintained under iron-rich ( $150 \mu \mathrm{M}$ iron nitrilotriacetate) or ironrestricted (180 $\mu \mathrm{M}$ 2,2-dipyridyl) conditions in vitro. The activities of PFOR and hydrogenase, and also production of acetate and $\mathrm{H}_{2}$, were markedly decreased or absent in iron-restricted trichomonads. Moreover, a decrease in activity of the hydrogenosomal malic enzyme, which is a non-Fe-S protein, was also observed. Impaired function of hydrogenosomes under iron-restricted conditions was compensated for by activation of the cytosolic pathway, mediating conversion of pyruvate to ethanol via acetaldehyde. This metabolic switch was fully reversible. Production of hydrogen by iron-restricted trichomonads was restored to the level of organisms grown under iron-rich conditions within $3 \mathrm{~h}$ after addition of $150 \mu \mathrm{M}$ iron nitrilotriacetate. Protein analysis of purified hydrogenosomes from iron-restricted cells showed decreased levels of proteins corresponding to PFOR, malic enzyme and ferredoxin. Accordingly, these cells displayed decreased steady-state level and synthesis of mRNAs encoding PFOR and hydrogenosomal malic enzyme. These data demonstrate that iron is essential for function of the hydrogenosome, show its involvement in the expression of hydrogenosomal proteins and indicate the presence of iron-dependent control of gene transcription in Tt. foetus.

\section{INTRODUCTION}

The hydrogenosome is a double-membrane-bound organelle present in trichomonads and other unicellular amitochondrial eukaryotes living in anaerobic or microaerobic conditions (Müller, 1993). The organelle was originally described and biochemically characterized in the parasitic flagellate Tritrichomonas foetus in the

Abbreviations: Fe-NTA, iron nitrilotriacetate; PFOR, pyruvate: ferredoxin oxidoreductase. early 70s (Lindmark \& Müller, 1973). Recently, it has attracted the attention of a number of cell evolutionary biologists due to its unusual feature, the production of hydrogen (Martin \& Müller, 1998), and its structural and biochemical similarity to mitochondria (Bui et al., 1996; Horner et al., 1996; Biagini et al., 1997; Hackstein et al., 1999). The main recognized function of the hydrogenosome is to generate ATP by means of a metabolic pathway which relies upon the activity of iron-sulfur $(\mathrm{Fe}-\mathrm{S})$ proteins: $[2 \mathrm{Fe}-2 \mathrm{~S}]$ ferredoxin (Johnson et al., 1990), [4Fe-4S] pyruvate:ferredoxin 
oxidoreductase (PFOR) (Williams et al., 1987) and [4Fe-4S] hydrogenase (Bui \& Johnson, 1996). It is likely that other, so far unidentified, $\mathrm{Fe}-\mathrm{S}$ proteins are present within the hydrogenosome, as indicated by complex EPR spectra (Ohnishi et al., 1980; Chapman et al., 1986). The core hydrogenosomal pathway in which $\mathrm{Fe}-\mathrm{S}$ proteins are involved utilizes pyruvate and malate as substrates and produces acetate, $\mathrm{CO}_{2}$ and $\mathrm{H}_{2}$ (Steinbuchel \& Müller, 1986a). Both hydrogenosomal substrates are formed in the cytoplasm as intermediates of glycolytic reactions (Hackstein et al., 1999). In Tt. foetus, glycolysis leads to the production of succinate, glycerol and negligible amounts of ethanol, which are excreted (Steinbuchel \& Müller, 1986b). Additionally, formate is produced in hydrogenosomes of the anaerobic chytrids (Hackstein et al., 1999). Formation of cytoplasmic pyruvate and its contribution to hydrogenosomal metabolism, however, remains unclear as activity of pyruvate kinase has not been detected in this organism (Hrdý \& Mertens, 1993). Malate, formed by cytosolic malate dehydrogenase (Hrdý, 1993), is imported into the hydrogenosome and converted to pyruvate by the activity of an NAD-dependent malic enzyme (Hrdý \& Mertens, 1993). PFOR, a key enzyme of the organelle, oxidatively decarboxylates pyruvate to acetyl-CoA. Electrons released during this reaction are transferred via ferredoxin to hydrogenase, producing $\mathrm{H}_{2}$. The CoA moiety of acetyl-CoA is transferred to succinate and subsequently succinyl-CoA serves as a substrate for succinate thiokinase, which transfers the energy for ATP production (Müller, 1988, 1993).

The importance of $\mathrm{Fe}-\mathrm{S}$ proteins in the carbohydrate metabolism of trichomonads (Gorrell et al., 1984; Marczak et al., 1983; Müller, 1988; Payne et al., 1993) and other anaerobes (Ellis et al., 1993; Weinbach et al., 1980) may explain the high nutritional requirements of these organisms for iron. It has been shown that addition of $50-100 \mu \mathrm{M} \mathrm{Fe}$ is required for optimal growth of Tt. foetus in vitro (Tachezy et al., 1996). Not surprisingly, availability of iron in the cells' environment affects metabolic activity of the hydrogenosome. Gorrell (1985) showed that Trichomonas vaginalis had an increased EPR signal for ferredoxin, and also an increased activity of PFOR and hydrogenase if the parasite was grown in a medium with the iron concentration elevated to $200 \mu \mathrm{M}$. In Tt. foetus, we have demonstrated that activity of PFOR considerably decreased and activity of hydrogenase became undetectable in cells maintained in iron-restricted media in comparison with those grown in an excess of iron (Tachezy et al., 1996). These phenomena could be explained either by a shortage of iron required for assembly of [ $\mathrm{Fe}-\mathrm{S}]$ clusters or by involvement of iron in mechanisms of hydrogenosomal protein expression, a process which is still poorly understood. The hydrogenosomes of trichomonads do not possess their own genome (Clemens \& Johnson, 2000). Thus the proteins operating in these organelles are encoded exclusively in the nucleus. Johnson et al. (1993) showed that expression of hydrogenosomal proteins closely resembles that known for the nucleus-encoded proteins of mitochondria. It includes synthesis of nascent protein on free ribosomes (Lahti \& Johnson, 1991), protein targeting by means of an amino-terminal leader sequence, translocation to the organelle and intrahydrogenosomal maturation, including cleavage of the leader sequence (Bradley et al., 1997). Whether and at which level (protein targeting, translation, mRNA stabilization, gene transcription) nutritional factors such as iron regulate expression of hydrogenosomal proteins has not been established.

In this paper we provide comparative biochemical data characterizing iron-dependent changes in metabolic fluxes in Tt. foetus, we show that iron is involved in expression of both $\mathrm{Fe}-\mathrm{S}$ and non-Fe-S proteins operating in hydrogenosomes, and we demonstrate that a putative iron-dependent regulation of hydrogenosomal proteins takes place at the transcriptional level.

\section{METHODS}

Organism and cultivation. Tt. foetus strain Lub-1 MIP (Tachezy et al., 1996) was maintained in trypticase-yeast extract-maltose medium (TYM) supplemented with $10 \%$ heat-inactivated horse serum at $\mathrm{pH} 7 \cdot 2$ (Diamond, 1957). Cells used for comparative studies were subcultured for 10 passages in medium without agar containing either $150 \mu \mathrm{M}$ iron nitrilotriacetate (Fe-NTA) or $180 \mu \mathrm{M}$ 2,2-dipyridyl (Sigma).

Cell fractionation. Cytosolic and hydrogenosome-rich fractions used for enzymic studies were obtained by differential centrifugation according to Drmota et al. (1996). To determine the activity of succinate thiokinase, the hydrogenosome-rich fraction was further subfractionated according to Jenkins et al. (1991) with a few modifications. The fraction was resuspended in a buffer containing $0.1 \mathrm{M}$ Tris/ $\mathrm{HCl}, 0 \cdot 175 \mathrm{M} \mathrm{KCl}$ and $100 \mu \mathrm{g}$ leupeptin $\mathrm{ml}^{-1}, \mathrm{pH} 7 \cdot 5$, and sonicated at $10 \mathrm{~W}$ for 3 cycles of $5 \times 1 \mathrm{~s}$ on ice. The sonicated fraction was centrifuged at $130000 \mathrm{~g}$ for $1 \mathrm{~h}$ and the supernatant was used for enzyme determinations.

Purified hydrogenosomes, used in the hydrogenosomal protein analysis, were obtained from the cell homogenate using a Percoll gradient according to Lahti et al. (1992). At least $90 \%$ latency of malic enzyme as a hydrogenosomal marker was found immediately after isolation of the organelles.

Determination of enzyme activities. All enzyme activities were assayed spectrophotometrically at $25^{\circ} \mathrm{C}$. Activities of PFOR (EC 1.2.7.1), hydrogenase (EC 1.18.99.1) and NADH:ferredoxin oxidoreductase (EC 1.18.1.3) were assayed as the rate of methyl viologen reduction monitored at $600 \mathrm{~nm}$. The assays were performed under anaerobic conditions using pyruvate and $\mathrm{H}_{2}$ as substrates for PFOR and hydrogenase, respectively (Kabícková et al., 1988), and NADH as substrate for NADH:ferredoxin oxidoreductase (Steinbuchel \& Müller, 1986a). Activities of adenylate kinase (EC 2.7.4.3) (Dinbergs \& Lindmark, 1989), malate dehydrogenase (EC 1.1.1.37) (Drmota et al., 1997), pyruvate decarboxylase (EC 4.1.1.1) (Črkasovová et al., 1984), succinate thiokinase (EC 6.2.1.5) (Cha \& Parks, 1964) and fumarate reductase (EC 1.3.1.6) were measured at $340 \mathrm{~nm}$ under anaerobic conditions as the rate of NADH oxidation. The assay mixture for measurement of fumarate reductase activity consisted of $100 \mathrm{mM}$ sodium phosphate buffer $\mathrm{pH} 7 \cdot 5$, $10 \mathrm{mM}$ DTT, $500 \mathrm{mM}$ fumarate and $10 \mathrm{mM} \mathrm{NADH}$. The 
activity of hydrogenosomal (EC 1.1.1.39) and cytoplasmic (EC 1.1.1.40) malic enzyme was measured aerobically at $340 \mathrm{~nm}$ as the rate of $\mathrm{NAD}^{+}$and $\mathrm{NADP}^{+}$reduction, respectively (Drmota et al., 1996), whilst NADH oxidase (EC 1.6.99.3) was determined as the rate of NADH oxidation (Tanabe, 1979).

Determination of metabolic end products. To determine production of organic acids and alcohols, intact trichomonads were resuspended in Doran's medium $(78 \mathrm{mM} \mathrm{NaCl}, 1.6 \mathrm{mM}$ $\mathrm{KCl}, 0.6 \mathrm{mM} \mathrm{CaCl}_{2}, 30 \mathrm{mM} \mathrm{NaH}_{2} \mathrm{PO}_{4}, 15 \mathrm{mM}$ maltose) to a density of $5 \times 10^{6}$ cells ml $\mathrm{m}^{-1}$ and $1 \mathrm{ml}$ aliquots were placed into $3 \mathrm{ml}$ vials sealed with vaccine stoppers. The vials were then flushed with nitrogen and incubated at $37^{\circ} \mathrm{C}$ for $30 \mathrm{~min}$. After incubation, the cells were removed by centrifugation and the end products determined by HPLC using a PL Hi-Plex $\mathrm{H}$ column. HPLC analysis was performed at $65^{\circ} \mathrm{C} ; 5 \mathrm{mM} \mathrm{H}_{2} \mathrm{SO}_{4}$ was used as the mobile phase. Acetate and succinate were monitored spectrophotometrically at $205 \mathrm{~nm}$, whilst ethanol and glycerol were followed by refractometry.

To determine hydrogen production, the trichomonads were incubated as above for $60 \mathrm{~min}$ and hydrogen concentrations measured in the gas phase using gas chromatography. The analysis was performed at room temperature using a molecular sieve 5A column connected to a thermistor detector; nitrogen was used as the carrier gas.

Time course experiment. Trichomonads maintained for 10 passages in the presence of $180 \mu \mathrm{M}$ 2,2-dipyridyl were resuspended in TYM or $50 \mathrm{mM}$ PBS-maltose $(137 \mathrm{mM} \mathrm{NaCl}$, $2.7 \mathrm{mM} \mathrm{KCl}, 4.6 \mathrm{mM} \mathrm{Na}_{2} \mathrm{HPO}_{4}, 1.5 \mathrm{mM} \mathrm{KH}_{2} \mathrm{PO}_{4}$ and $50 \mathrm{mM}$ maltose, pH 7.2) supplemented with $150 \mu \mathrm{M}$ Fe-NTA. Aliquots of $1 \mathrm{ml}$ suspension containing $5 \times 10^{7}$ cells were immediately placed into $3 \mathrm{ml}$ vials as above and incubated at $37^{\circ} \mathrm{C}$. Hydrogen production was determined by gas chromatography after various time intervals.

SDS-PAGE and Western blot analysis. SDS-PAGE and Western blotting were used to analyse the protein composition of Percoll-purified hydrogenosomes. SDS-PAGE was performed on a Bio-Rad minislab gel apparatus using 12 or $18 \%$ gel, and $5 \%$ stacking gel. Electrophoretically resolved proteins were stained with silver (Swain \& Ross, 1995) or transferred to nitrocellulose membrane to be probed with polyclonal rabbit antibodies against hydrogenosomal malic enzyme (Drmota et al., 1996), ferredoxin and $\alpha$-subunit of succinate thiokinase (the latter two antibodies were kindly provided by P. Johnson, UCLA, USA). Quantitative analysis was performed using ScanPack software (Biometra).

Amino acid sequencing. Proteins were separated by SDSPAGE, transblotted onto a PVDF membrane (Millipore) and stained with Coomassie brilliant blue. The bands of interest were excised and the proteins sequenced from their amino terminus by Edman degradation.

Nucleic acid isolation. Genomic DNA and total RNA were isolated from $\mathrm{Tt}$. foetus by modified guanidium thiocyanate methods as described by Bowtell (1987) and Wang \& Wang (1985), respectively.

Northern blot analysis. Total RNA was size-separated on $1.2 \%$ agarose $/ 2 \mathrm{M}$ formaldehyde gel and transferred to a nylon membrane (Hybond $\mathrm{N}$; Amersham). Blots were hybridized with radiolabelled DNA probes for hydrogenosomal malic enzyme and PFOR. Subsequently, the membranes were stripped down and rehybridized with DNA probe for $\beta$-tubulin as a control.

Nuclear run-on assay. Synthesis of nascent mRNA was investigated by means of a modified run-on assay according to
Ullu \& Tschudi (1990). Briefly, trichomonads were washed and resuspended in transcription buffer $(150 \mathrm{mM}$ sucrose, $20 \mathrm{mM}$ potassium glutamate, $3 \mathrm{mM} \mathrm{MgCl}_{2}, 1 \mathrm{mM}$ DTT, $10 \mu \mathrm{g}$ leupeptin $\mathrm{ml}^{-1}, 20 \mathrm{mM}$ HEPES/Tris $\mathrm{pH} \mathrm{7.9)}$ and permeabilized in the presence of $1 \mathrm{mg}$ lysolecithin $\mathrm{ml}^{-1}$. The suspension was mixed with the transcription mixture \{4 mM ATP, $2 \mathrm{mM}$ GTP, $2 \mathrm{mM}$ CTP, $50 \mathrm{mM}$ creatine phosphate, $1.2 \mathrm{mg}$ creatine phosphokinase $\mathrm{ml}^{-1},\left[\alpha_{-}{ }^{32} \mathrm{P}\right] \mathrm{UTP}$ [3 $\mathrm{kCi} \mathrm{mmol}^{-1}$ (111 TBq mmol ${ }^{-1}$; Amersham)], $50 \mathrm{mM}$ potassium glutamate, $1.5 \mathrm{mM} \mathrm{MgCl}_{2}, 5 \mathrm{mM}$ DTT, $1 \mathrm{mM}$ HEPES and incubated for $20 \mathrm{~min}$ at $35^{\circ} \mathrm{C}$. Nascent RNA was isolated by TRIzol extraction according to the protocol of the manufacturer (Gibco-BRL). ${ }^{32}$ P-labelled transcripts were hybridized to DNA-specific probes immobilized on nitrocellulose. Blots were analysed using storage phosphor autoradiography (PhosphorImager SI; Molecular Dynamics) and signals quantified by means of Multi Analyst software (Bio$\mathrm{Rad})$.

Preparation of DNA probes. All probes were prepared by PCR amplification using specific primer pairs ( $\beta$-tubulin: CAT CGT CCC ATC TCC AAA GG and AAT GGA ACA AGG TTG ACA GC; malic enzyme: AGG AAG AAC GTG ACC GCC and GTT GCC GAT ATC GTG GTC; PFOR: GAY GGH ACH GTN GGH GC and TCR WAD GCC CAR CCR TC; 16S rRNA: GGT GGT GCA TGG CCG and GTA GGT GAA CCT GCA GAA GGA TCA). For Northern blot analysis, PCR products were purified on agarose gels followed by phenol/chloroform extraction and labelled with $\left[\alpha^{32}\right] \mathrm{dATP}$ using a Random Primed DNA Labelling Kit (Boehringer Mannheim). In the run-on assay, PCR products were inserted into a pGEM vector (TA Cloning Kit; Stratagene) and immobilized on nitrocellulose as a probe. Nucleotide sequences of all PCR products were verified with an automatic ABI Prism 310 gene analyser (Perkin Elmer).

\section{RESULTS}

\section{Effect of iron on carbohydrate metabolism}

Studies of carbohydrate metabolism revealed that trichomonads are able to switch between cytoplasmic and hydrogenosomal catabolism of pyruvate according to availability of iron. Activities of hydrogenosomal enzymes involved in pyruvate metabolism (malic enzyme, PFOR, hydrogenase, NADH:ferredoxin oxidoreductase) were dramatically reduced in trichomonads grown for 10 subcultures in the presence of iron chelator (180 $\mu \mathrm{M}$ 2,2-dipyridyl) in comparison with those cells maintained under iron-rich conditions (Table 1). Consequently, production of acetate and hydrogen, the major hydrogenosomal end products, was lowered or ceased, respectively, in these organisms (Table 2). It is noteworthy that shortage of iron caused a decrease in enzymic activity for both $\mathrm{Fe}-\mathrm{S}$ (hydrogenase, PFOR) and non-Fe-S (malic enzyme) proteins. Decreased metabolism of pyruvate in hydrogenosomes was compensated for by increased conversion of pyruvate to ethanol in the cytoplasm. The activity of NADPdependent malic enzyme and pyruvate decarboxylase increased about twofold and 42-fold, respectively, in the cells grown under iron-restricted conditions. Ethanol became the major metabolic end product in the chelatortreated cells, whilst only a negligible amount of ethanol was produced by trichomonads grown in iron-enriched 
Table 1. Effect of iron on enzymic activities involved in carbohydrate metabolism in hydrogenosomes and cytosol of Tt. foetus

\begin{tabular}{|c|c|c|c|c|c|c|c|c|c|}
\hline \multirow[t]{2}{*}{ Enzyme } & \multicolumn{3}{|c|}{ Iron $(150 \mu \mathrm{M})$} & \multicolumn{3}{|c|}{ 2,2-Dipyridyl $(180 \mu \mathrm{M})$} & \multicolumn{3}{|c|}{ 2,2-Dipyridyl + iron* } \\
\hline & Activity $\dagger$ & SEM & $n$ & Activity $\dagger$ & SEM & $n$ & Activity $†$ & SEM & $n$ \\
\hline \multicolumn{10}{|l|}{ Hydrogenosome } \\
\hline $\begin{array}{l}\text { NAD-dependent malic } \\
\text { enzyme }\end{array}$ & $236 \cdot 7$ & $82 \cdot 5$ & 4 & $15 \cdot 0$ & $10 \cdot 4$ & 10 & $419 \cdot 6$ & $22 \cdot 8$ & 3 \\
\hline PFOR & $549 \cdot 8$ & $362 \cdot 6$ & 11 & $50 \cdot 0$ & $2 \cdot 0$ & 8 & $414 \cdot 2$ & $117 \cdot 0$ & 4 \\
\hline Hydrogenase & $1629 \cdot 3$ & $798 \cdot 4$ & 9 & 0 & 0 & 11 & $4230 \cdot 3$ & $367 \cdot 4$ & 3 \\
\hline $\begin{array}{l}\text { NADH: ferredoxin } \\
\text { oxidoreductase }\end{array}$ & $407 \cdot 7$ & $161 \cdot 2$ & 4 & $44 \cdot 0$ & $17 \cdot 7$ & 11 & $799 \cdot 0$ & $140 \cdot 5$ & 3 \\
\hline Adenylate kinase & $143 \cdot 5$ & $32 \cdot 4$ & 3 & $118 \cdot 0$ & $20 \cdot 2$ & 3 & ND & & \\
\hline Succinyl thiokinase & $205 \cdot 2$ & $40 \cdot 3$ & 4 & $182 \cdot 4$ & $47 \cdot 6$ & 3 & ND & & \\
\hline \multicolumn{10}{|l|}{ Cytosol } \\
\hline $\begin{array}{l}\text { NADP-dependent malic } \\
\text { enzyme }\end{array}$ & $209 \cdot 4$ & $99 \cdot 5$ & 12 & $477 \cdot 0$ & $183 \cdot 5$ & 13 & $199 \cdot 0$ & $14 \cdot 0$ & 3 \\
\hline Malate dehydrogenase & $3089 \cdot 0$ & $795 \cdot 3$ & 3 & $2217 \cdot 7$ & $851 \cdot 0$ & 4 & $4504 \cdot 7$ & $355 \cdot 6$ & 4 \\
\hline Pyruvate decarboxylase & $1 \cdot 0$ & 0 & 6 & $42 \cdot 6$ & $24 \cdot 1$ & 14 & $1 \cdot 0$ & 0 & 3 \\
\hline Fumarate reductase & $165 \cdot 0$ & $34 \cdot 8$ & 9 & $104 \cdot 0$ & $13 \cdot 5$ & 14 & $119 \cdot 0$ & $5 \cdot 9$ & 3 \\
\hline NADH oxidase & $407 \cdot 7$ & $161 \cdot 2$ & 4 & $44 \cdot 0$ & $18 \cdot 7$ & 11 & $799 \cdot 0$ & $140 \cdot 5$ & 3 \\
\hline
\end{tabular}

ND, Not determined.

*2,2-Dipyridyl $(180 \mu \mathrm{M})$-treated cells were transferred to media containing $180 \mu \mathrm{M}$ 2,2-dipyridyl and $150 \mu \mathrm{M}$ Fe-NTA for 10 subsequent subcultures before determination of enzyme activities.

†Values are mean specific activities expressed in $\mathrm{nmol} \mathrm{min}^{-1}(\mathrm{mg} \text { protein })^{-1}$.

Table 2. Effect of iron on production of cytosolic and hydrogenosomal end products of carbohydrate metabolism

\begin{tabular}{|lcrrrr|}
\hline \multirow{2}{*}{ End product } & \multicolumn{2}{c}{ Iron $(\mathbf{1 5 0} \boldsymbol{\mu M})$} & & \multicolumn{2}{c|}{ 2,2-Dipyridyl $(\mathbf{1 8 0} \boldsymbol{\mu M})$} \\
\cline { 2 - 3 } \cline { 5 - 6 } & Production* & SEM & & Production* & SEM \\
& & & & & \\
\hline Acetate & $318 \cdot 4$ & $10 \cdot 8$ & & $51 \cdot 1$ & $5 \cdot 6$ \\
Hydrogen & $27 \cdot 5$ & $2 \cdot 2$ & & $3 \cdot 7$ & $1 \cdot 2$ \\
Ethanol & $7 \cdot 5$ & $1 \cdot 8$ & & $950 \cdot 1$ & $68 \cdot 6$ \\
Glycerol & $39 \cdot 9$ & $4 \cdot 8$ & & $71 \cdot 0$ & $5 \cdot 7$ \\
Succinate & $478 \cdot 9$ & $20 \cdot 2$ & & $356 \cdot 6$ & $17 \cdot 7$ \\
\hline
\end{tabular}

*Values are rates of production expressed in $\mathrm{nmol}(30 \mathrm{~min})^{-1}$ $(\mathrm{mg} \text { protein })^{-1}$ and are means of four determinations.

media. Availability of iron did not significantly influence activities of the hydrogenosomal enzymes involved in ATP metabolism (adenylate kinase and succinate thiokinase), or of cytosolic fumarate reductase and malate dehydrogenase. Iron-restricted conditions, however, markedly lowered the activity of cytoplasmic $\mathrm{NADH}$ oxidase.

To investigate whether the changes in pyruvate metabolism were reversible, the chelator-treated cells were transferred to chelator $(180 \mu \mathrm{M}$ 2,2-dipyridyl)-containing media supplemented with $150 \mu \mathrm{M}$ Fe-NTA for 10 subsequent subcultures and then the enzymic activities of interest were determined. As is apparent from Table 1 , the activity of hydrogenosomal enzymes increased to comparable or even higher levels than those determined in trichomonads continuously maintained under ironrich conditions. Conversely, activities of cytoplasmic enzymes involved in pathways leading to production of ethanol (pyruvate decarboxylase, NADP-dependent malic enzyme) decreased after addition of iron. Finally, we monitored the switch from cytoplasmic to hydrogenosomal pyruvate metabolism in a time-course experiment. The chelator-treated cells were resuspended in either nutritionally rich TYM medium containing $180 \mu \mathrm{M}$ 2,2-dipyridyl or in simple maltose-PBS medium, both supplemented with $150 \mu \mathrm{M}$ Fe-NTA, and the production of hydrogen as a marker hydrogenosomal end product was monitored for $3 \mathrm{~h}$ (Fig. 1). Traces of hydrogen appeared after $1 \mathrm{~h}$ and reached a comparable level to that found in chelator-untreated cells after $3 \mathrm{~h}$ in TYM medium. Production of hydrogen by cells incubated in iron-containing PBS was also observed. However, it appeared later (after $2 \mathrm{~h}$ incubation) and remained considerably lower than that produced by trichomonads incubated in TYM medium.

\section{Iron-dependent changes in protein profile of hydrogenosomes}

To determine whether the observed changes in enzymic activities reflect iron-dependent changes in expression of hydrogenosomal proteins, we compared the protein 


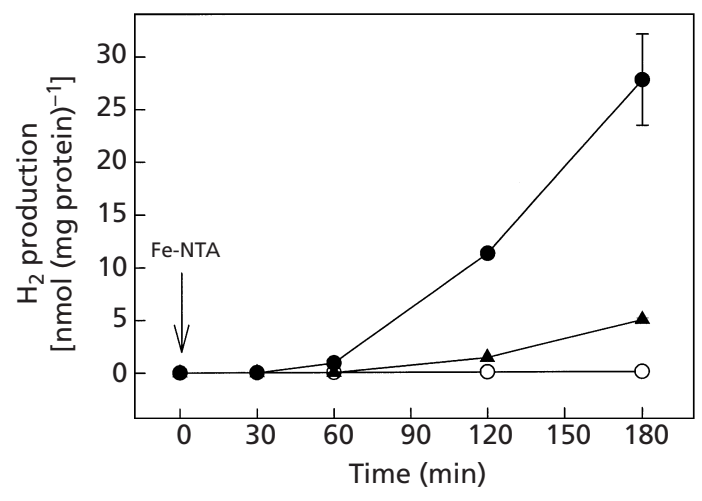

Fig. 1. Stimulation of hydrogen production in iron-deprived Tt. foetus after addition of iron. Cells maintained for 10 passages in the presence of iron chelator (2,2-dipyridyl) were resuspended in TYM $(\boldsymbol{O})$ or maltose-PBS $(\boldsymbol{A})$ supplemented with $150 \mu \mathrm{M}$ iron as Fe-NTA. Control cells were incubated in TYM with $180 \mu \mathrm{M}$ 2,2-dipyridyl (O). After incubation of cell suspensions at $37^{\circ} \mathrm{C}$ for defined time periods, production of hydrogen was determined by gas chromatography.

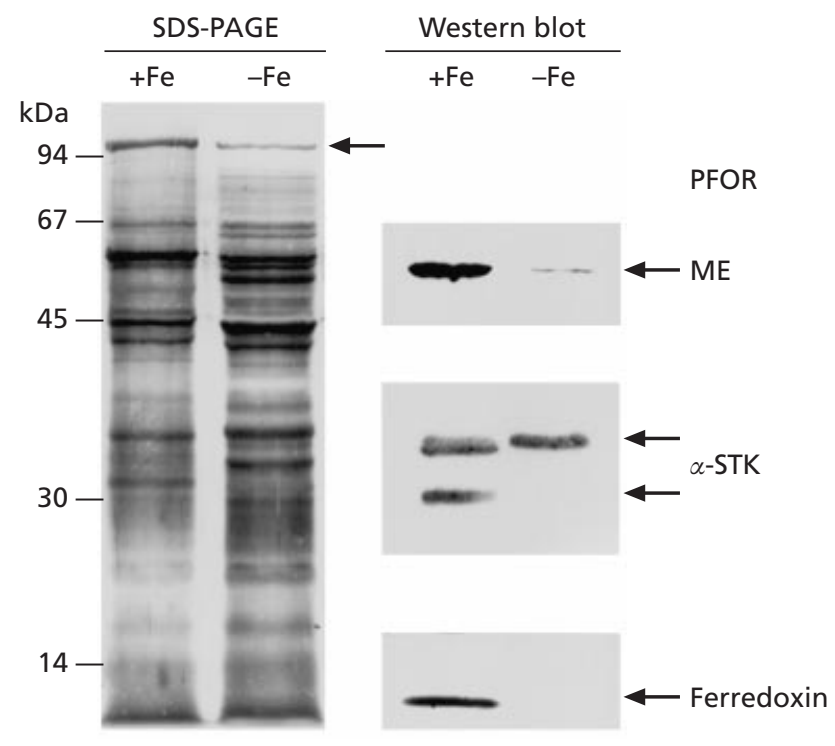

Fig. 2. Iron-dependent changes in profile of hydrogenosomal proteins. Hydrogenosomes were isolated from Tt. foetus maintained for 10 subcultures in TYM medium supplemented with $150 \mu \mathrm{M}$ Fe-NTA (+Fe) or $180 \mu \mathrm{M}$ 2,2-dipyridyl (-Fe). Protein profiles were analysed on $12 \%$ acrylamide gels by means of SDS-PAGE and by Western blotting using polyclonal antibodies against hydrogenosomal malic enzyme (ME), ferredoxin and $\alpha$-subunit of succinate thiokinase (STK). PFOR corresponds to the $120 \mathrm{kDa}$ band on SDS-PAGE gels, as confirmed by amino acid sequence analysis.

profile of hydrogenosomes isolated from trichomonads grown in iron-rich or iron-restricted media. As is apparent from Fig. 2, protein profiles of highly purified hydrogenosomes were markedly different. The amount of a prominent $120 \mathrm{kDa}$ protein corresponding to PFOR

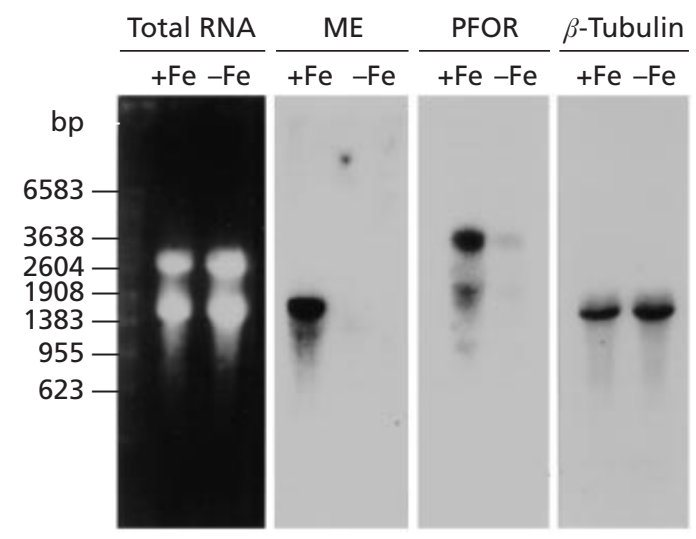

Fig. 3. Comparison of steady-state concentrations of mRNA encoding hydrogenosomal malic enzyme (ME) and PFOR in Tt. foetus maintained under iron-rich $(+\mathrm{Fe})$ and iron-restricted $(-\mathrm{Fe})$ conditions. Amounts of total RNA loaded onto each lane were standardized according to the level of $\beta$-tubulin mRNA.

was reduced to about $40 \%$ in chelator-treated cells as estimated by densitometry (the identity of this $120 \mathrm{kDa}$ protein was verified by amino acid microsequencing; data not shown). In iron-rich hydrogenosomes, ferredoxin appeared as a $14 \mathrm{kDa}$ band using Western blot analysis (Fig. 2). No comparable band was observed in hydrogenosomes of chelator-treated cells. In addition to differences in levels of $\mathrm{Fe}-\mathrm{S}$ proteins, we also observed iron-dependent changes in the amount of a protein corresponding to NAD-dependent malic enzyme $(60 \mathrm{kDa})$. The level of malic enzyme was reduced in hydrogenosomes of chelator-treated cells to about $3 \%$ of that from iron-rich hydrogenosomes. These results indicate that iron is required for expression of both Fe-S and non-Fe-S proteins involved in hydrogenosomal metabolism of pyruvate.

Consistent with the enzyme activity, antibody against the $\alpha$-subunit of succinate thiokinase recognized a similar amount of proteins apparent as a $38 \mathrm{kDa}$ band. However, another peptide was identified using this antibody $(32 \mathrm{kDa})$ which was present only in cells maintained under iron-rich conditions. To confirm specificity of the antibody, both bands were analysed by amino acid microsequencing. The analysis showed identity between the $\mathrm{N}$-terminal sequences of the 38 and $32 \mathrm{kDa}$ peptides detected in iron-rich cells and the $38 \mathrm{kDa}$ peptide of chelator-treated organisms (ASGNLPLLFS). Further iron-dependent differences were observed in the peptides of molecular mass $65,57,49,48$ and $33 \mathrm{kDa}$, which were present in considerably higher concentrations in chelator-treated cells.

\section{Effect of iron on transcription of genes encoding PFOR and malic enzyme}

Northern blot analysis was performed to determine whether chelator-treated cells possess reduced levels of steady-state mRNA encoding PFOR and hydro- 


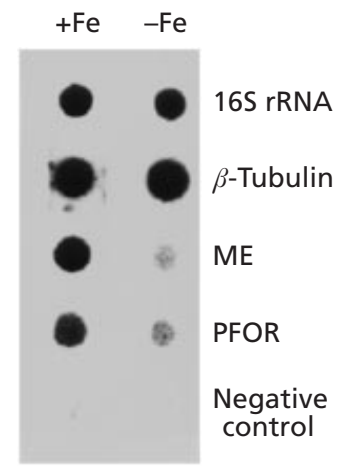

Fig. 4. Transcriptional levels of malic enzyme (ME) and PFOR in $T t$. foetus maintained under iron-rich $(+\mathrm{Fe})$ and iron-restricted $(-\mathrm{Fe})$ conditions. The levels were measured by nuclear run-on assays using lysolecithin-permeabilized cells. Dot blots contained DNA clones with fragments of $16 \mathrm{~S}$ RNA, $\beta$-tubulin, ME and PFOR genes. The blots were hybridized with nascent ${ }^{32} \mathrm{P}$ labelled transcripts. Plasmid pGEM DNA was used as negative control.

genosomal malic enzyme. Consistent with the protein levels, reduced levels of PFOR and malic enzyme mRNA were found (Fig. 3). To exclude the possibility that iron starvation resulted in generalized reduction of mRNAs, the blots were stripped and rehybridized with a probe identifying $\beta$-tubulin mRNA. A comparable signal for this mRNA was found in the organisms maintained under both iron-rich and iron-restricted conditions (Fig. 3).

We further measured the synthesis of nascent mRNA encoding PFOR and malic enzyme to determine whether lower mRNA levels resulted from decreased transcription of corresponding genes. The synthesis of mRNA was monitored in detergent-permeabilized cells using a modified run-on assay. As is apparent from Fig. 4, the synthesis of malic enzyme and PFOR mRNA was reduced in the cells maintained for 10 subcultures in iron-restricted medium to about 14 and $27 \%$, respectively. In contrast, no changes in transcription of two control genes ( $\beta$-tubulin, 16S RNA) were observed in these organisms. The decreased synthesis of malic enzyme and PFOR mRNA, together with observed changes in the steady-state mRNA levels indicate that iron is required for transcription of genes encoding essential proteins involved in pyruvate metabolism within hydrogenosomes.

\section{DISCUSSION}

Differences in carbon flow between Tt. foetus cells maintained under iron-rich or iron-restricted conditions are summarized in a proposed metabolic map (Fig. 5). Trichomonads grown in excess of iron produced nearly equimolar concentrations of succinate and acetate in the cytoplasm and hydrogenosome, respectively, which is consistent with observations by others (Steinbuchel $\&$ Müller, 1986b). In chelator-treated cells, hydrogeno- somal metabolism dramatically decreased, resulting in a succinate to acetate molar ratio of about $7: 1$. As expected, decreased acetate production was accompanied by reduced hydrogen production. Conversely, the activities of hydrogenosomal NADdependent malic enzyme, PFOR and hydrogenase were low or undetectable in hydrogenosomes isolated from iron-restricted organisms. To compensate for the decreased metabolism of hydrogenosomes, the trichomonads showed increased cytosolic fermentation of pyruvate to ethanol, which became the dominant fermentation end product derived from glucose.

Intriguing questions raised by these observations concern how pyruvate is formed in Tt. foetus cytosol and the source of pyruvate serving as a substrate for hydrogenosome metabolism. Although trichomonads metabolize glucose via the Embden-Meyerhoff pathway, leading to formation of pyruvate in $T$. vaginalis (Mertens et al., 1992), activity of pyruvate kinase is either very low or absent in Tt. foetus (Hrdý \& Mertens, 1993). In both species, pyruvate is alternatively produced from malate which is formed from phosphoenolpyruvate via oxalacetate (Drmota et al., 1997; Hrdý, 1993). Conversion of malate to pyruvate is catalysed by a cytosolic NADP-dependent malic enzyme (Hrdý, 1993; our unpublished results). Reduced NADP could be regenerated by the activity of an NADP-dependent glycerol-3-phosphate dehydrogenase leading to the production of glycerol (Chapman et al., 1985; Steinbuchel \& Müller, 1986b). However, low production of glycerol in $T t$. foetus observed by us and also by others $(7 \%$ of fermentation products derived from glucose; Steinbuchel \& Müller, 1986b) is not sufficient to account for the redox balance in cells grown under iron-rich conditions. Therefore, we propose that in Tt. foetus malate preferentially enters the hydrogenosome where it is converted to pyruvate by the hydrogenosomal NADdependent malic enzyme. Contribution of cytosolic pyruvate as the hydrogenosomal substrate seems to be of lesser importance. Similar substrate preference has been found previously in hydrogenosomes of the anaerobic chytrids Piromyces sp. E2 and Neocallimastix sp. L2 (Hackstein et al., 1999).

Interestingly, malate-dependent formation of pyruvate in the cytosol became essential for carbohydrate metabolism of $\mathrm{Tt}$. foetus maintained under ironlimited conditions (Fig. 5). In these cells, oxidative decarboxylation of malate to pyruvate catalysed by NADP-dependent malic enzyme is coupled to the conversion of pyruvate to acetaldehyde mediated by pyruvate decarboxylase. Subsequently, acetaldehyde is reduced to ethanol by alcohol dehydrogenase in a reaction accompanied by reoxidation of NADP, a critical step for maintenance of the redox balance. In addition, production of glycerol slightly increases in iron-restricted cells, which may further contribute to NADP reoxidation.

Iron-dependent modulation of cytosolic/hydrogenosomal carbon metabolism has been observed 


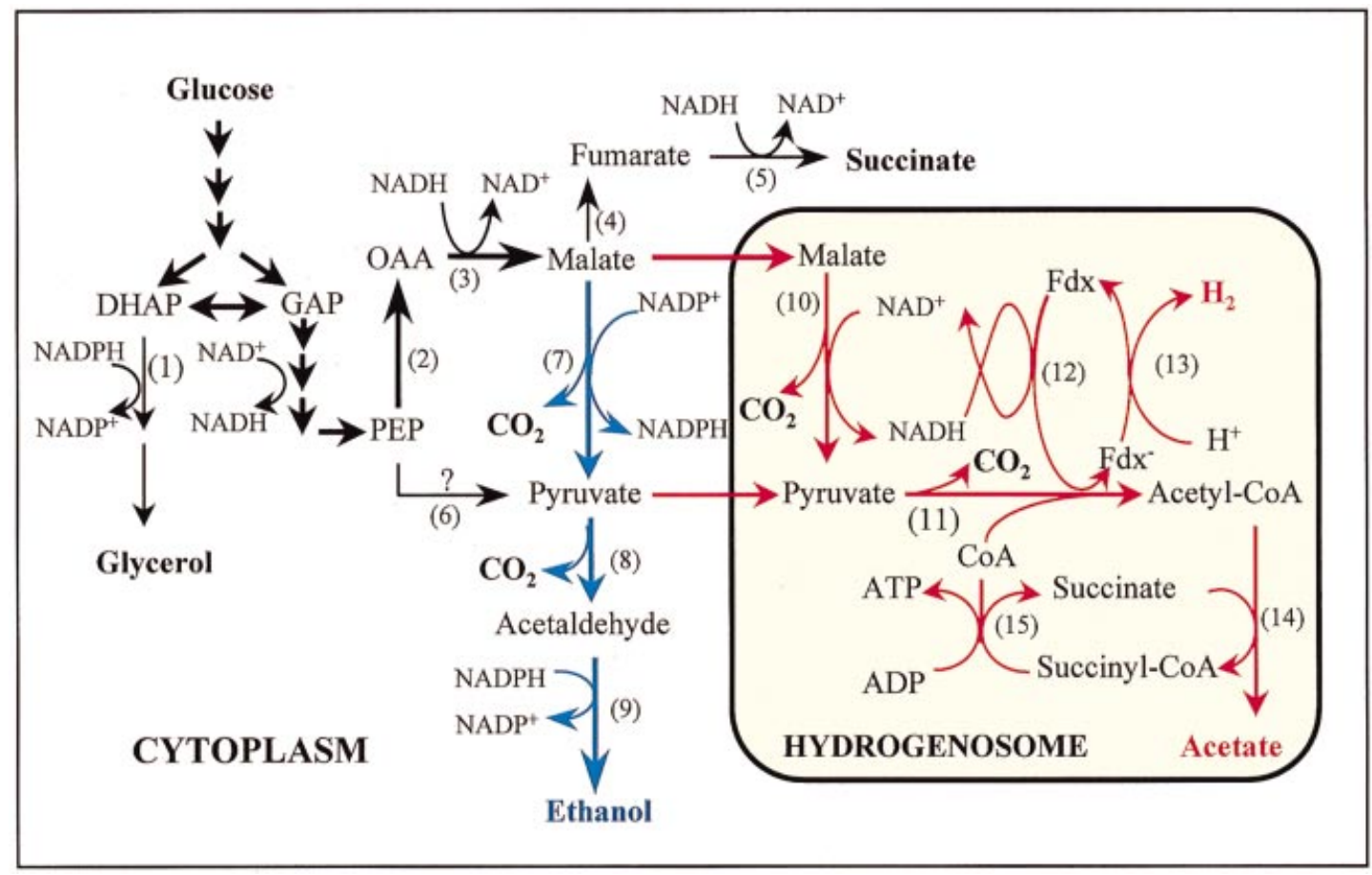

Fig. 5. Iron-dependent changes in carbohydrate catabolism in Tt. foetus. Arrows indicate the assumed physiological direction of the reaction. Red arrows indicate the pathways which are active in trichomonads maintained under iron-rich conditions, whilst blue arrows indicate the pathways which are activated under iron-restricted conditions. Bold lines indicate the pathway of the major overall carbon flow.1, Glycerol-3-phosphate dehydrogenase; 2 , phosphoenolpyruvate carboxykinase; 3, malate dehydrogenase; 4, fumarase; 5, fumarate reductase; 6, pyruvate kinase; 7, NADP-dependent malic enzyme; 8, pyruvate decarboxylase; 9, alcohol dehydrogenase; 10, NAD-dependent malic enzyme; 11, pyruvate:ferredoxin oxidoreductase; 12, NAD:ferredoxin oxidoreductase; 13, hydrogenase; 14, acetate:succinate CoAtransferase; 15, succinate thiokinase. (The map was modified with permission of Elsevier Science Publishers from Steinbuchel \& Müller, 1986a, b.)

previously in T. vaginalis (Gorrell, 1985). Unlike Tt. foetus, the human parasite possesses a cytosolic pathway converting pyruvate to lactate, which is a major product of its carbohydrate metabolism. Gorrell (1985) demonstrated that production of lactate decreases, whilst release of hydrogenosomal end products increases, if $T$. vaginalis is maintained in iron-enriched TYM medium.

It is noteworthy that changes in carbohydrate metabolism similar to those caused by iron-restricted conditions in Tt. foetus have been observed in trichomonads with in-vitro-induced resistance to metronidazole (Cerkasovová et al., 1984; Kulda, 1999). The mode of action of metronidazole, the major drug utilized for treatment of trichomoniasis, resides in its metabolic activation within hydrogenosomes (Müller, 1986). Here, the drug is reduced by ferredoxin-donated electrons which are generated during oxidative decarboxylation of pyruvate or malate. In metronidazole-resistant strains, electrons required for drug activation are not generated as activities of the key enzymes PFOR, malic enzyme and hydrogenase disappear. As in the case of iron-restricted cells, metronidazole-resistant organisms compensate for impaired function of hydrogenosomes by increased rate of cytosolic fermentation to ethanol
(Cerkasovová et al., 1984) or lactate (Kulda et al., 1993). In the present experiments we showed that irondependent metabolic changes were fully reversible upon addition of excess iron. Similarly, changes in pyruvate metabolism in the early stages of drug resistance reverted if pressure of metronidazole was released (Kabičková et al., 1988). In light of these observations it is tempting to speculate that mechanisms mediating iron-dependent changes in carbohydrate fluxes and those involved in development of metronidazole resistance in trichomonads may have a related molecular basis.

To determine at which level iron-dependent regulation of hydrogenosomal metabolism takes place, we compared cells of Tt. foetus grown under iron-rich and ironrestricted conditions with regard to (i) profiles of hydrogenosomal proteins, (ii) steady-state levels of mRNA encoding PFOR and hydrogenosomal malic enzyme, and (iii) synthesis of nascent mRNAs. Profound changes in protein composition were observed. The levels of two $\mathrm{Fe}-\mathrm{S}$ proteins, PFOR and ferredoxin, as well as NAD-dependent malic enzyme (a non-Fe-S protein), were markedly decreased in chelator-treated cells. The decreased protein levels of both hydrogenosomal enzymes corresponded to decreased steady- 
state levels of pertinent mRNAs on the Northern blots. To distinguish whether the lowered steady-state mRNA levels were due to changes in mRNA stabilization or transcription we performed nuclear run-on assays. These experiments clearly showed that synthesis of nascent mRNA encoding PFOR and malic enzyme is lower in chelator-treated cells. These results indicate that the iron-dependent changes in activity of core metabolic pathways within hydrogenosomes are regulated at the transcriptional level.

Interestingly, Western blot analysis showed differences in the pattern of succinate thiokinase $\alpha$-subunit $(\alpha$-STK) isoforms relative to availability of iron, although comparable enzyme activities were detected in cells grown under iron-rich and iron-restricted conditions. It has been shown in T. vaginalis that $\alpha$-STK is encoded by three genes of identical length. However, three bands of different mobility have been recognized using anti- $\alpha$ STK serum (Lahti et al., 1994). The differences in protein mobility have been ascribed to different posttranslational modifications or to conformational differences (Lahti et al., 1994). In our experiments, presence of the lighter peptide $(32 \mathrm{kDa})$ was irondependent, whilst the heavier peptide $(38 \mathrm{kDa})$ was produced under both iron-restricted and iron-rich conditions. Alderete et al. (1998) identified three T. vaginalis genes with either identical (AP51-2) or highly similar (AP51-1, AP51-3) nucleotide sequences known to encode the $\beta$-subunit of succinate thiokinase ( $\beta$-STK). Northern blot analysis has shown that levels of AP51-1 and AP51-3 mRNAs depend on iron availability, whilst the level of AP51-2 mRNA was iron-independent. Thus it is plausible that in trichomonads iron regulates expression of various isoforms of both $\alpha$-STK and $\beta$ STK. Alternatively, iron could be involved in posttranslational modification of the proteins, as was demonstrated for the hydrogenosomal malic enzyme (Drmota et al., 1996).

Iron-dependent changes in enzyme activity have been extensively studied in the $\mathrm{Fe}-\mathrm{S}$ protein aconitase present in the cytosol of higher eukaryotes. In this enzyme, the loss of enzymic activity under iron-restricted conditions is caused by disassembly of $[\mathrm{Fe}-\mathrm{S}]$ clusters, while the level of the protein remains unchanged (Yu et al., 1992). Loss of $[\mathrm{Fe}-\mathrm{S}]$ clusters is associated with an alternative function of aconitase as an iron regulatory protein (IRP) (Kim et al., 1995). Apoaconitase mediates posttranscriptional regulation of two molecules central to cellular iron homeostasis, the transferrin receptor and ferritin (Rouault \& Klausner, 1997). Recently, a homologue of cytosolic aconitase has been found in the marine ciliate Eufolliculina uhligi, although its function as an IRP has not been proven (Markmann-Mulisch et al., 1999). It is not known whether IRPs also operate in trichomonads; however, their presence is unlikely. Trichomonads do not posses either aconitase activity (I. Hrdý, unpublished) or a transferrin receptor (Tachezy et al., 1996). Moreover, our experiments demonstrated the effect of iron on the transcriptional level only. Nevertheless, the presence of iron-dependent post-trans- lational regulation cannot be ruled out. Transcriptional control of iron-regulated genes is well-known in bacteria. They possess a histidine-rich protein designated Fur (ferric uptake regulator) which acts as a repressor together with iron (Crosa, 1997; Hantke, 1984). The main function of Fur is to turn off the expression of genes involved in iron uptake under iron-rich conditions. To our knowledge, iron-dependent control of protein expression of the type reported here for trichomonads is different from other mechanisms of iron-dependent regulation described so far. In trichomonads, iron is involved (i) in positive transcriptional control, and (ii) in regulation of expression of proteins involved in core energy metabolism. Further studies are required to obtain detailed information on the molecular mechanisms of the iron regulatory system of trichomonads, which might be unique to these unicellular eukaryotes.

\section{ACKNOWLEDGEMENTS}

We thank Professor Miklos Müller for critical reading of the manuscript, and Dr Jannet Kiethly (The Wadsworth Center, Albany, USA) and Dr Karel Bezouška (Charles University, Prague, Czech Republic) for amino acid sequence analysis. The work was supported by the Grant Agency of the Czech Republic (204/00/156; J. T.), and the Ministry of Education of the Czech Republic (VS 96 142; J.K.).

\section{REFERENCES}

Alderete, J. F., Engbring, J., Lauriano, C. M. \& O’Brien, J. L. (1998). Only two of the Trichomonas vaginalis triplet AP51 adhesins are regulated by iron. Microb Pathog 24, 1-16.

Biagini, G. A., Finlay, B. J. \& Lloyd, D. (1997). Evolution of the hydrogenosome. FEMS Microbiol Lett 155, 133-140.

Bowtell, D. D. (1987). Rapid isolation of eukaryotic DNA. Anal Biochem 162, 463-465.

Bradley, P. J., Lahti, C. J., Plumper, E. \& Johnson, P. J. (1997). Targeting and translocation of proteins into the hydrogenosome of the protist Trichomonas: similarities with mitochondrial protein import. EMBO J 16, 3484-3493.

Bui, E. T. \& Johnson, P. J. (1996). Identification and characterization of $[\mathrm{Fe}]$-hydrogenases in the hydrogenosome of Trichomonas vaginalis. Mol Biochem Parasitol 76, 305-310.

Bui, E. T., Bradley, P. J. \& Johnson, P. J. (1996). A common evolutionary origin for mitochondria and hydrogenosomes. Proc Natl Acad Sci US A 93, 9651-9656.

Čerkasovová, A., Čerkasov, J. \& Kulda, J. (1984). Metabolic differences between metronidazole resistant and susceptible strains of Tritrichomonas foetus. Mol Biochem Parasitol 11, 105-118.

Cha, S. \& Parks, R. E., Jr (1964). Succinate thiokinase. Purification of the enzyme from pig heart. J Biol Chem 239, 1961-1967.

Chapman, A., Linstead, D. J., Lloyd, D. \& Williams, J. (1985). ${ }^{13} \mathrm{C}-$ NMR reveals glycerol as an unexpected major metabolite of the protozoan parasite Trichomonas vaginalis. FEBS Lett 191, 287-292.

Chapman, A., Cammack, R., Linstead, D. J. \& Lloyd, D. (1986). Respiration of Trichomonas vaginalis. Components detected by electron paramagnetic resonance spectroscopy. Eur J Biochem 156, 193-198. 
Clemens, D. L. \& Johnson, P. J. (2000). Failure to detect DNA in hydrogenosomes of Trichomonas vaginalis by nick translation and immunomicroscopy. Mol Biochem Parasitol 106, 307-313.

Crosa, J. H. (1997). Signal transduction and transcriptional and posttranscriptional control of iron-regulated genes in bacteria. Microbiol Mol Biol Rev 61, 319-336.

Diamond, L. S. (1957). The establishment of various trichomonads of animals and man in axenic cultures. J Parasitol 43, 488-490.

Dinbergs, I. D. \& Lindmark, D. G. (1989). Tritrichomonas foetus: purification and characterization of hydrogenosomal ATP:AMP phosphotransferase (adenylate kinase). Exp Parasitol 69, 150-156.

Drmota, T., Proost, P., Van Ranst, M., Weyda, F., Kulda, J. \& Tachezy, J. (1996). Iron-ascorbate cleavable malic enzyme from hydrogenosomes of Trichomonas vaginalis: purification and characterization. Mol Biochem Parasitol 83, 221-234.

Drmota, T., Tachezy, J. \& Kulda, J. (1997). Isolation and characterization of cytosolic malate dehydrogenase from Trichomonas vaginalis. Folia Parasitol (Praha) 44, 103-108.

Ellis, J. E., Williams, R., Cole, D., Cammack, R. \& Lloyd, D. (1993). Electron transport components of the parasitic protozoon Giardia lamblia. FEBS Lett 325, 196-200.

Gorrell, T. E. (1985). Effect of culture medium iron content on the biochemical composition and metabolism of Trichomonas vaginalis. J Bacteriol 161, 1228-1230.

Gorrell, T. E., Yarlett, N. \& Müller, M. (1984). Isolation and characterization of Trichomonas vaginalis ferredoxin. Carlsberg Res Commun 49, 259-268.

Hackstein, J. H., Akhmanova, A., Boxma, B., Harhangi, H. R. \& Voncken, F. G. (1999). Hydrogenosomes: eukaryotic adaptations to anaerobic environments. Trends Microbiol 7, 441-447.

Hantke, K. (1984). Cloning of the repressor protein gene of ironregulated systems in Escherichia coli K-12. Mol Gen Genet 197, 337-341.

Horner, D. S., Hirt, R. P., Kilvington, S., Lloyd, D. \& Embley, T. M. (1996). Molecular data suggest an early acquisition of the mitochondrion endosymbiont. Proc R Soc Lond Ser B Biol Sci 263, 1053-1059.

Hrdý, I. (1993). Purification and partial characterization of cytosolic malate dehydrogenase from Tritrichomonas foetus. Folia Parasitol (Praha) 40, 181-185.

Hrdý, I. \& Mertens, E. (1993). Purification and partial characterization of malate dehydrogenase (decarboxylating) from Tritrichomonas foetus hydrogenosomes. Parasitology 107, 379-385.

Jenkins, T. M., Gorrell, T. E., Müller, M. \& Weitzman, P. D. (1991). Hydrogenosomal succinate thiokinase in Tritrichomonas foetus and Trichomonas vaginalis. Biochem Biophys Res Commun 179, 892-896.

Johnson, P. J., d'Oliveira, C. E., Gorrell, T. E. \& Müller, M. (1990). Molecular analysis of the hydrogenosomal ferredoxin of the anaerobic protist Trichomonas vaginalis. Proc Natl Acad Sci US A 87, 6097-6101.

Johnson, P. J., Lahti, C. J. \& Bradley, P. J. (1993). Biogenesis of the hydrogenosome in the anaerobic protist Trichomonas vaginalis. $J$ Parasitol 79, 664-670.

Kabíčková, H., Kulda, J., Čerkasovová, A. \& Němcová, H. (1988). Metronidazole resistant Tritrichomonas foetus: activities of hydrogenosomal enzymes in course of development of anaerobic resistance. Acta Univ Carol Biol 30, 513-519.

Kim, H. Y., Klausner, R. D. \& Rouault, T. A. (1995). Translational repressor activity is equivalent and is quantitatively predicted by in vitro RNA binding for two iron-responsive element-binding proteins, IRP1 and IRP2. J Biol Chem 270, 4983-4986.

Kulda, J. (1999). Trichomonads, hydrogenosomes and drug resistance. Int J Parasitol 29, 199-212.

Kulda, J., Tachezy, J. \& Čerkasovová, A. (1993). In vitro induced anaerobic resistance to metronidazole in Trichomonas vaginalis. J Eukaryot Microbiol 40, 262-269.

Lahti, C. J. \& Johnson, P. J. (1991). Trichomonas vaginalis hydrogenosomal proteins are synthesized on free polyribosomes and may undergo processing upon maturation. Mol Biochem Parasitol 46, 307-310.

Lahti, C. J., d'Oliveira, C. E. \& Johnson, P. J. (1992). Beta-succinylcoenzyme A synthetase from Trichomonas vaginalis is a soluble hydrogenosomal protein with an amino-terminal sequence that resembles mitochondrial presequences. J Bacteriol 174, 6822-6830.

Lahti, C. J., Bradley, P. J. \& Johnson, P. J. (1994). Molecular characterization of the alpha-subunit of Trichomonas vaginalis hydrogenosomal succinyl CoA synthetase. Mol Biochem Parasitol 66, 309-318.

Lindmark, D. G. \& Müller, M. (1973). Hydrogenosome, a cytoplasmic organelle of the anaerobic flagellate Tritrichomonas foetus, and its role in pyruvate metabolism. J Biol Chem 248, 7724-7728.

Marczak, R., Gorrell, T. E. \& Müller, M. (1983). Hydrogenosomal ferredoxin of the anaerobic protozoon, Tritrichomonas foetus. $J$ Biol Chem 258, 12427-12433.

Markmann-Mulisch, U., Reiss, B. \& Mulisch, M. (1999). Cell typespecific gene expression in the cell cycle of the dimorphic ciliate Eufolliculina ubligi. Mol Gen Genet 262, 390-399.

Martin, W. \& Müller, M. (1998). The hydrogen hypothesis for the first eukaryote. Nature 392, 37-41.

Mertens, E., Van Schaftingen, E. \& Müller, M. (1992). Pyruvate kinase from Trichomonas vaginalis, an allosteric enzyme stimulated by ribose 5-phosphate and glycerate 3-phosphate. Mol Biochem Parasitol 54, 13-20.

Müller, M. (1986). Reductive activation of nitroimidazoles in anaerobic microorganisms. Biochem Pharmacol 35, 37-41.

Müller, M. (1988). Energy metabolism of protozoa without mitochondria. Annu Rev Microbiol 42, 465-488.

Müller, M. (1993). The hydrogenosome. J Gen Microbiol 139, 2879-2889.

Ohnishi, T., Lloyd, D., Lindmark, D. G. \& Müller, M. (1980). Respiration of Tritrichomonas foetus: components detected in hydrogenosomes and in intact cells by electron paramagnetic resonance spectrometry. Mol Biochem Parasitol 2, 39-50.

Payne, M. J., Chapman, A. \& Cammack, R. (1993). Evidence for an $[\mathrm{Fe}]$-type hydrogenase in the parasitic protozoan Trichomonas vaginalis. FEBS Lett 317, 101-104.

Rouault, T. \& Klausner, R. (1997). Regulation of iron metabolism in eukaryotes. Curr Top Cell Regul 35, 1-19.

Steinbuchel, A. \& Müller, M. (1986a). Anaerobic pyruvate metabolism of Tritrichomonas foetus and Trichomonas vaginalis hydrogenosomes. Mol Biochem Parasitol 20, 57-65.

Steinbuchel, A. \& Müller, M. (1986b). Glycerol, a metabolic end product of Trichomonas vaginalis and Tritrichomonas foetus. Mol Biochem Parasitol 20, 45-55.

Swain, M. \& Ross, N. W. (1995). A silver stain protocol for proteins yielding high resolution and transparent background in sodium dodecyl sulfate-polyacrylamide gels. Electrophoresis 16, 948-951. 
Tachezy, J., Kulda, J., Bahníková, I., Suchan, P., Rázga, J. \& Schrével, J. (1996). Tritrichomonas foetus: iron acquisition from lactoferrin and transferrin. Exp Parasitol 83, 216-228.

Tanabe, M. (1979). Trichomonas vaginalis: NADH oxidase activity. Exp Parasitol 48, 135-143.

Ullu, E. \& Tschudi, C. (1990). Permeable trypanosome cells as a model system for transcription and trans-splicing. Nucleic Acids Res 18, 3319-3326.

Wang, A. L. \& Wang, C. C. (1985). A linear double-stranded RNA in Trichomonas vaginalis. J Biol Chem 260, 3697-3702.

Weinbach, E. C., Takeuchi, T., Claggett, C. E., Inohue, F., Kon, H. \& Diamond, S. D. (1980). Role of iron-sulfur proteins in the electron transport system of Entamoeba histolytica. Arch Invest Med (Mex) 11, 75-81.

Williams, K., Lowe, P. N. \& Leadlay, P. F. (1987). Purification and characterization of pyruvate: ferredoxin oxidoreductase from the anaerobic protozoon Trichomonas vaginalis. Biochem J 246, 529-536.

Yu, Y., Radisky, E. \& Leibold, E. A. (1992). The iron-responsive element binding protein. Purification, cloning, and regulation in rat liver. J Biol Chem 267, 19005-19010.

Received 9 June 2000; revised 31 August 2000; accepted 21 September 2000. 